\title{
Selecting support for new mine development - a case study from Impala Platinum Ltd
}

\author{
L.J. Gardner Impala Platinum Ltd, South Africa
}

M.H. Fox Impala Platinum Ltd, South Africa

N.L. Conley Impala Platinum Ltd, South Africa

\begin{abstract}
Over the past decade, Impala Platinum Ltd has executed several major mining projects in Southern Africa involving the sinking of vertical and/or decline shafts together with the associated ore body access development. The ground control challenges inherent in these different projects have necessitated the use of multiple support strategies for different project phases, support unit types and combinations.

The design and specification of support systems have required the evaluation of multiple parameters, often in an iterative manner. Common criteria include depth and associated rock mass response, block size, excavation dimensions, proposed mining methodology, mining equipment and planned cycle times. Occasionally, other variables also need to be considered, such as corrosion resistance, microseismicity, ground swelling, etc.

Whilst the advisory reports issued for the individual phases of each project highlight the envisaged rockrelated hazards and strategies to address them, the overarching strategy is generally not provided. This paper details the approach used at Impala to select the appropriate support philosophies, systems and units/types for each unique situation.
\end{abstract}

\section{$1 \quad$ Introduction}

Over the past decade, Impala Platinum Ltd has executed several major mining projects. These projects involved the sinking of vertical and/or decline shafts, together with the associated ore body access development, at different mining depths and in a variety of geotechnical environments. This paper sets down the approach used in selecting appropriate support philosophies, systems and units/types to address the many ground control challenges encountered at the different projects.

\section{Geological and geotechnical background}

The Bushveld Complex is an extremely large, two billion year-old saucer-shaped layered igneous intrusion. Located in the northern part of South Africa, it hosts the world's largest known reserves of platinum. In plan, the complex has a clover-leaf shape, consisting of four compartments or limbs. It is unique both in its size (it covers some $66,000 \mathrm{~km}^{2}$ ) and in the economic importance of its minerals.

Two rich horizons are typically exploited for Platinum Group Metals (PGMs) - the Merensky economic horizon and UG2 chromitite seam. The PGMs recovered include platinum, palladium, rhodium, ruthenium and iridium, together with quantities of gold, nickel, copper and several other metals and compounds. The complex comprises a diversity of igneous rocks, with compositions from ultramafic to felsic. Typical rock types include norites, anorthosites, felspathic pyroxenite, pegmatoidal pyroxenite and chromitite.

Average rock densities range from $2.7 \mathrm{t} / \mathrm{m}^{3}$ for the noritic and anorthositic rock types to more than $4.1 \mathrm{t} / \mathrm{m}^{3}$ for the chromitite rocks. Uniaxial compressive strengths for the different rock types vary between $80 \mathrm{MPa}$ for chromitite to more than $160 \mathrm{MPa}$ for the more brittle anorthosites. The lower strength rock types (chromitite, pegmatoidal pyroxenite) generally behave in a ductile manner when loaded, whereas the stronger rock types (norites and anorthosites) behave in a more brittle fashion. 
Virgin vertical stress levels are in the order of 28 to $30 \mathrm{MPa} / 1,000 \mathrm{~m}$ of depth. The major principal stress is normally horizontal and oriented along the ore bodies' strike direction, the intermediate principal stress is horizontal and dip-orientated and the minor principal stress is near-vertical. Average k-ratios, i.e. the ratio between vertical and horizontal stress, vary from more than three at shallow depths to approximately 1.2 at $1,200 \mathrm{~m}$ below surface.

\section{$3 \quad$ Locality and mining method}

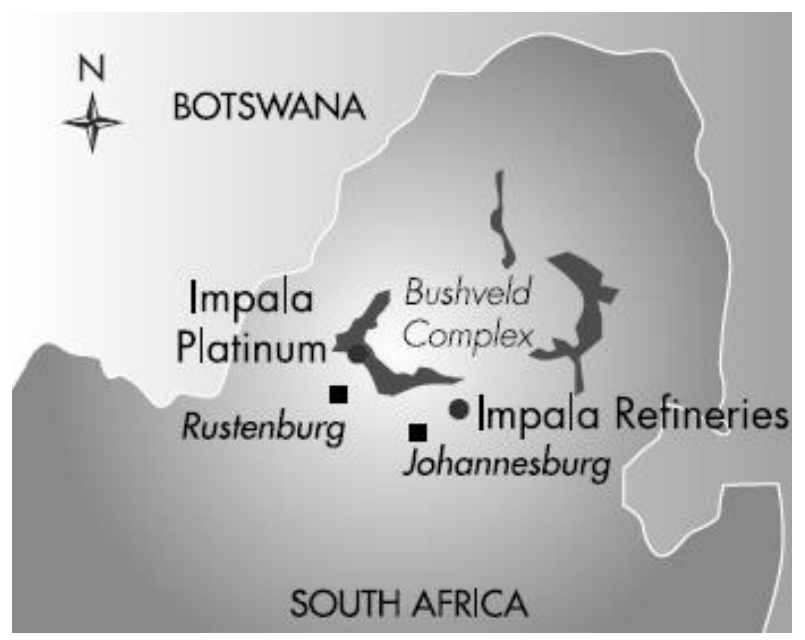

\section{Figure 1 Locality of Rustenburg operations}

Impala Platinum Ltd is the world's second largest Platinum producer. The group owns and operates mines, processing plants and refineries in South Africa and Zimbabwe.

The company's main mining lease area (Rustenburg operations) is situated some $30 \mathrm{~km}$ north of Rustenburg in the North West Province of South Africa, along the western lobe of the Bushveld Complex (Figure 1). The lease area covers $260 \mathrm{~km}^{2}$.

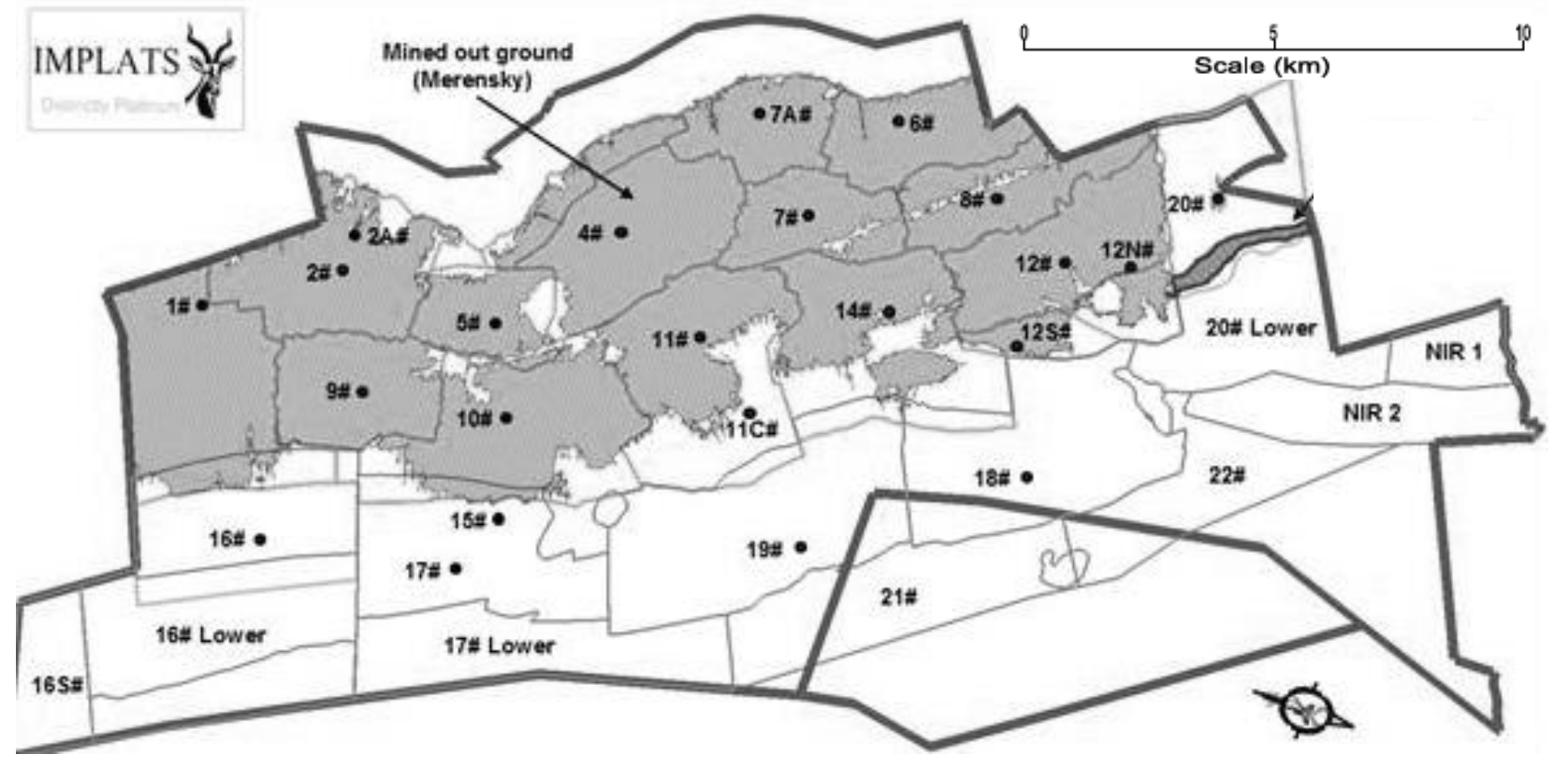

Figure 2 Different shaft blocks on Impala Rustenburg lease area

The geological sequence in the lease area dips at approximately 9 degrees to the north-east. The Merensky and UG2 ore bodies are separated by between 45 and 125 metres, with this middling increasing across the property from north to south. 
Apart from limited open pit operations, fourteen shaft systems are used for access and mining purposes, at depths ranging from 30 to 1,200 metres below surface. A further three shaft systems are currently under construction, namely No. 16 shaft, No. 17 shaft and No. 20 shaft (Figure 2).

Underground mining operations generally follow conventional tabular mining practice (some trackless room-and-pillar mining also takes place). From the vertical shaft systems, a series of off-reef haulages (normally flat, but sometimes together with inclines / declines), crosscuts and travelling ways provide access to the ore body. On the reef horizon, raises and winzes are developed to establish an infrastructure for stoping operations. Stoping is conducted using labour-intensive narrow-reef techniques such as scattered breast mining.

More than 35,000 people are employed underground on the lease area to extract approximately 14 million tonnes of ore per annum. This yields some 900,000 ounces of platinum, plus additional quantities of other associated platinum group and base metals.

\section{$4 \quad$ Support design process}

The design and specification of a support system involves evaluating a number of parameters, often in an iterative manner. These include, amongst others:

- Depth and rock mass response - shallow versus deep versus intermediate.

- Block size - large versus small, solid versus fractured.

- Excavation height - safe initial and subsequent examination.

- Excavation width - beam strength, tendon length, with or without anchors.

- Matching support principles, types and combinations to prevailing conditions.

- Merging machinery, methodology, dimensions and cycle time.

- Other features - corrosion resistance, microseismicity, swelling, etc.

\subsection{Depth and rock mass response}

Impala currently mines at depths ranging from 30-1,300 m below surface, with fourth-generation shafts planning to extend this to more than $1,800 \mathrm{~m}$. Over this wide range of depths, the rock mass response to mining undergoes several changes (Figure 3).

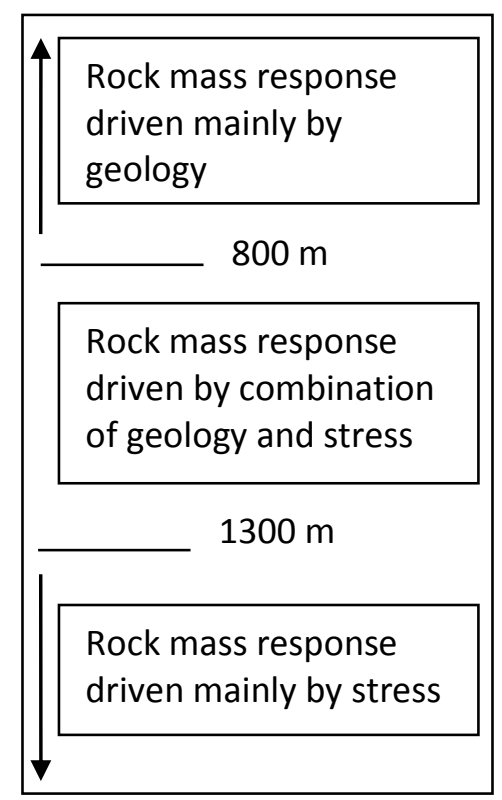

Figure 3 Rock mass response 
At depths less than $800 \mathrm{~m}$, rock mass response is geologically-controlled, i.e. falls of ground originate along geological structural boundaries such as joints, faults, dykes and veins.

At depths greater than $1,300 \mathrm{~m}$, rock mass response is more stress-driven, with all rock types fracturing to some degree.

In the zone between these two depths, fracturing takes place selectively, with the brittle 'whiter' anorthositic types rocks fracturing first, followed by the 'greyer' noritic rock types.

\subsection{Block size - large versus small versus fractured}

To prevent falls of ground in tunnels, potentially-loose individual blocks of rock need to be kept in place. In shallow conditions in the Bushveld Complex, rock block sizes (as dictated by near-vertical joint spacing) are typically in the order of $1.5 \times 1.5 \mathrm{~m}$. This implies that they can be pinned in place by tendons installed on a $1.0 \times 1.0 \mathrm{~m}$ pattern (Figure 4), with additional tendons required to pin odd blocks that may occur when the excavations traverse abnormal geological structures (e.g. faults, dykes, veins, etc.).

Where joint frequency increases, such as at No. 20 shaft, block sizes reduce to the point where individual blocks can no longer be pinned in place without substantially reducing the tendon spacing (Figure 5). Ground conditions are typically classified in the mine's Code of Practice (Gardner, 2012) as 'blocky ground' when the block size is less than $0.5 \times 0.5 \mathrm{~m}$. In such cases, shotcrete or wire mesh is normally installed together with the primary support tendons to provide full area coverage.

In fractured conditions, the fracture slab size also varies - the 'whiter' anorthositic rock types, with higher feldspar content, tend to fracture in thin 'plates' (Figure 6) while the 'greyer' noritic rock types tend to fracture in large slabs (Figure 7). As shown in Figure 6, if not confined, the rock continues to slab - often to more than $1.0 \mathrm{~m}$ from the original excavation position. Tendons alone do not provide adequate support.

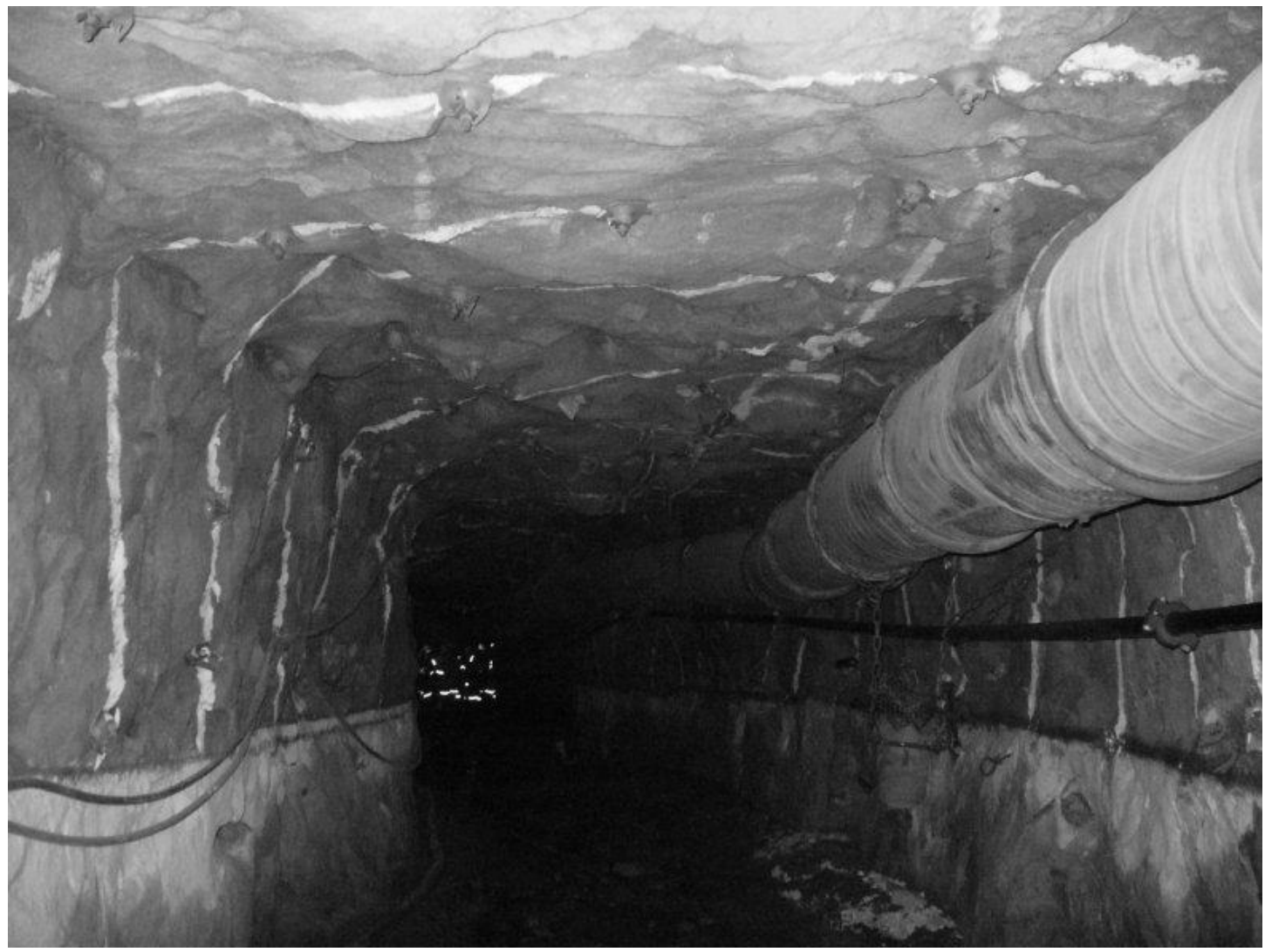

Figure 4 Typical Bushveld ground conditions and support pattern (photo not from Impala) 


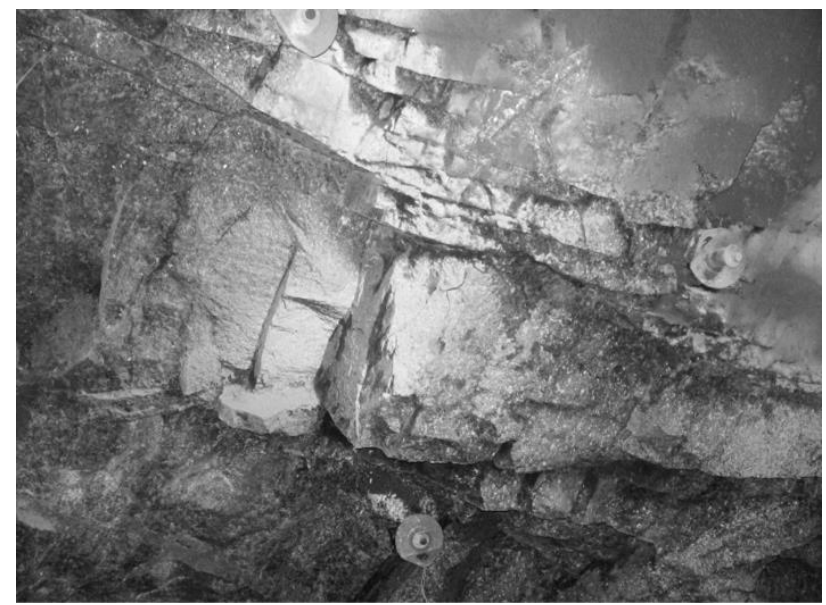

Figure 5 Typical 'blocky ground' conditions as at No. 20 shaft

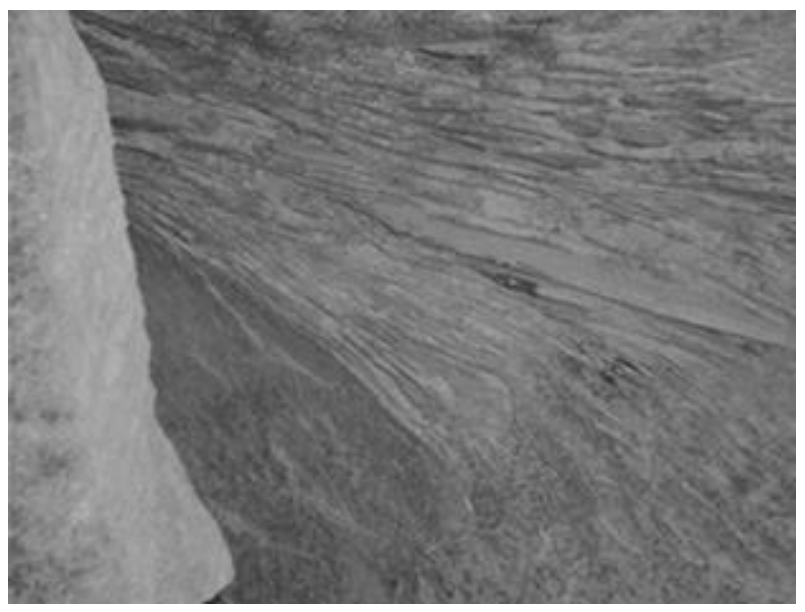

Figure 6 Thin 'plate' type stress-fracturing in anorthositic rock type at No. 16 shaft

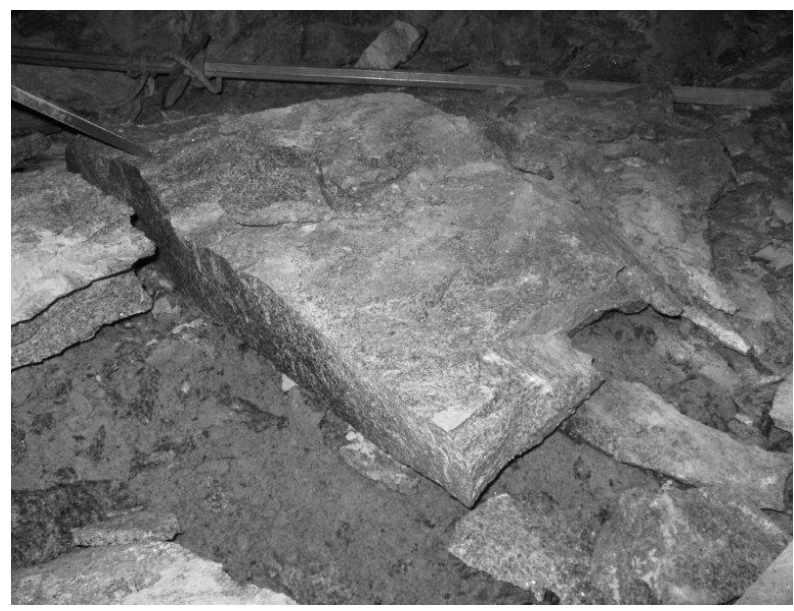

Figure 7 Thick 'slab' type stress-fractured block in noritic rock type at No. 17 shaft

\subsection{Excavation height and the complication of safe subsequent examination}

The face area of most development ends has traditionally been examined, barred and made safe manually, working off the muck pile to attain a working height of 2-3 $\mathrm{m}$. Some attempts have been made to bar from LHD buckets and/or scissor lift baskets, although these are generally not ergonomically ideal. In some large trackless development ends, barring of the face area is conducted by mechanical scaler or by 'rattling' using the drill rig, ensuring zero personnel exposure during this hazardous operation. 
In ends supported only by tendons, once the area has been supported, the face has advanced and the end has been equipped, safe subsequent examination and barring / dressing of loose rocks is limited by several issues, including:

- The practical height which a manual pinch bar (even a lightweight aluminium version) can reach without requiring undue effort and/or placing the user in danger from being too close beneath the area being barred.

- Equipment or machinery situated in the excavation, e.g. conveyor, chairlift, monorail, pumping or electrical equipment, pipes or electrical cables.

- The need to keep traffic (people, vehicles or rock) moving through the area.

In light of the above, several strategies are employed to minimise risk:

- Typical footwall haulages, that are supported using tendons only, are limited to a maximum $3.5 \mathrm{~m}$ high (equipped height) to allow safe dressing with a $3.0 \mathrm{~m}$ long aluminium pinch bar.

- In areas with non-typical ground conditions (whether due to block size or fracturing), sidewall tendons are specified to within a maximum of $2.0 \mathrm{~m}$ above the footwall.

- Where increased height is required (e.g. due to ventilation requirements, trackless vehicle size or installed equipment):

- Multiple mining cuts are typically employed if the end height exceeds $4.5 \mathrm{~m}$ for handheld drilling operations or $6.0 \mathrm{~m}$ for mechanised (drill rig) drilling operations.

- Additional cable anchors are installed in the sidewalls if the end height exceeds $5.0 \mathrm{~m}$.

- Some type of full areal coverage is normally specified for the hanging wall and sidewalls, to within a maximum of $2.0 \mathrm{~m}$ above the footwall.

\subsection{Relating tendon length to excavation purpose and dimension}

When designing an appropriate support system, the dimensions, purpose and anticipated lifespan of the excavation need to be taken into consideration. There is a vast difference between the support requirements for a main shaft station (large, long-term, used by many people), as opposed to those of an in-stope redevelopment end (small, short-term, limited access by people).

To assist with the process, Impala designs are based on one of two approaches, as listed below:

- Adopting the approach proposed by Barton et al. (1974), which makes use of a concept termed the Excavation Support Ratio (ESR). An appropriate ESR value is allocated to each typical type of excavation, based on the purpose of the individual excavation, its anticipated life expectancy and the actual excavation width or span. Excavations are thus allocated into three classes based on risk level, namely:

- Critical excavations (ESR of 1.3), e.g. shafts, shaft station breakaways, loading boxes and pump stations - the loss of such excavations would have a serious, long-term effect on production, or result in the stoppage of the shaft or mine for a significant period.

- Long-term excavations (ESR of 1.6), e.g. shaft tip areas and other off-station development, workshops, declines and main rock passes - the loss of such excavations would have a serious, medium-term effect on production.

- Production excavations (ESR of 2.0), e.g. footwall strike drives, stope panels - the loss of such excavations would have a minor, short-term effect on production.

Obviously, critical ends present a higher risk to both production and safety; hence the support requirements in areas with an ESR of 1.3 are more stringent than those in areas with an ESR of 1.6 or two. 
- Meeting tendon length and support resistance criteria based on fallout heights determined by an analysis of historical fall of ground data, as proposed by Dr M K C Roberts and described by Jager and Ryder (1999). This approach is normally used in established mines, which have a large database of falls of ground. The normal primary support system must provide sufficient support resistance to cater for at least $95 \%$ of all potential falls within the specific local area and/or ground control district.

For greenfields projects, the Barton approach is normally adopted as there is no historical data available for the area in question. On a practical level, typical tendon length requirements (depending on tendon type and bond length) for long term excavations are in the order of:

- For excavations less than $4.5 \mathrm{~m}$ wide, 2.1-2.4 m long tendons.

- For ends 4.5-15 m wide, 2.1-2.4 m long tendons, supplemented by $4.5 \mathrm{~m}$ long cable anchors (kept within $6.0 \mathrm{~m}$ of the advancing face at all times).

Although it is theoretically possible to specify $3.0 \mathrm{~m}$ long tendons (rather than $4.5 \mathrm{~m}$ long cable anchors), the use of such long units has proven to be impractical.

Development ends up to a maximum of $6.0 \mathrm{~m}$ wide are normally mined as a straight face. Ends greater than $6.0 \mathrm{~m}$ wide typically carry a shoulder, with the one end leading the other by a minimum of $6.0 \mathrm{~m}$. The leading end must be pre-supported with the required secondary support (cable anchors) before blasting the lagging shoulder. The cable anchors for the lagging face must also not lag for more than $6.0 \mathrm{~m}$ behind the lagging face (6.0 $\mathrm{m}$ maximum after the blast).

\subsection{Matching support principles, types and combinations to conditions}

As shown in the mindmap (Figure 8), the prevailing geotechnical conditions present two separate risk areas, namely a safety risk and a stability risk. The safety risk generally applies to the development crew, while the stability risk applies for the life of the excavation.

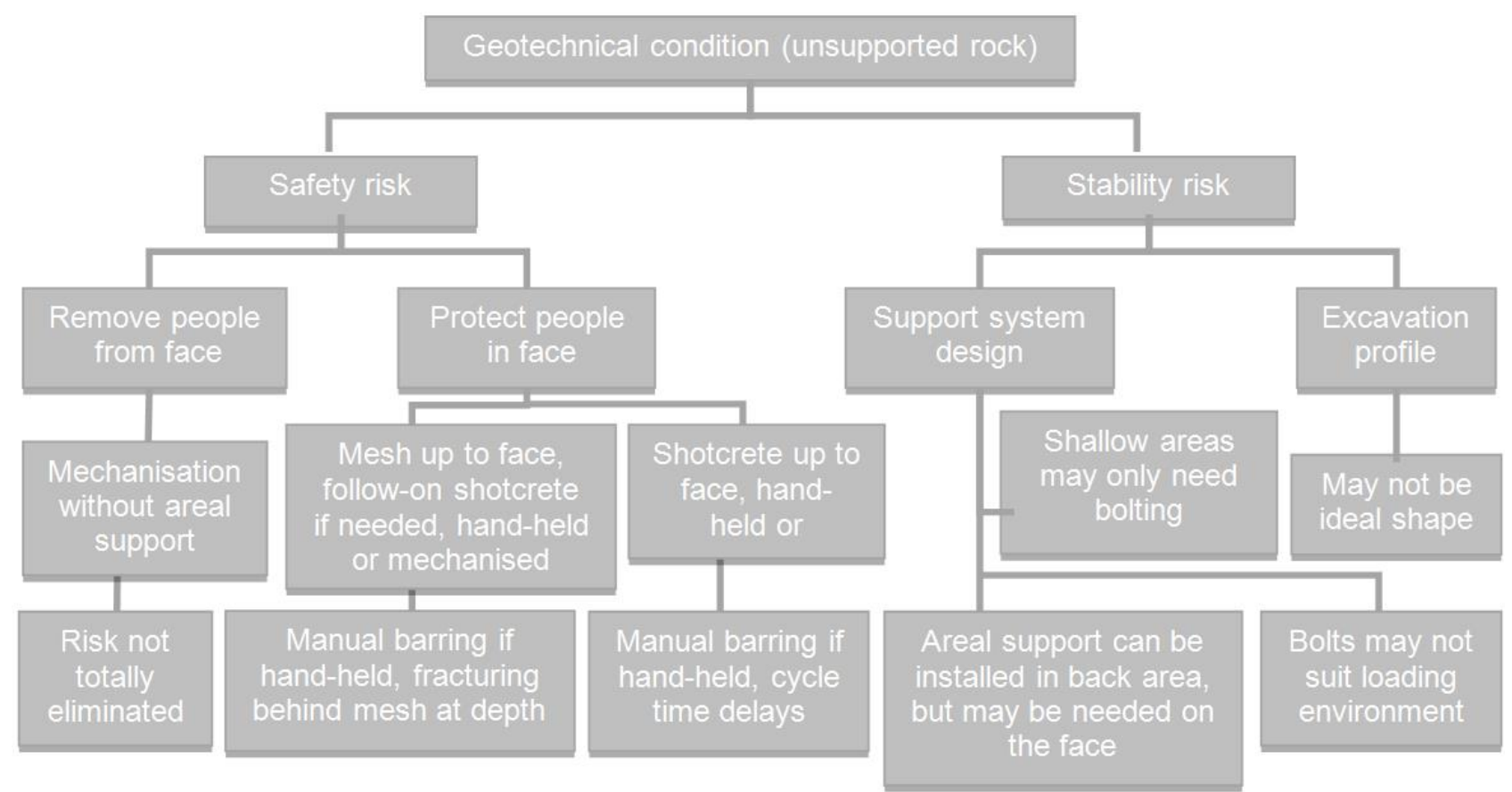

Figure 8 Geotechnical condition risk mindmap

In addressing the safety risk, there are two systems currently employed on the different projects that apply to the 'protect people in face' category, namely: 
- For the shallow, blocky environment, sheets of welded 'Aussie' mesh pinned in place by Split Set ${ }^{\mathrm{TM}}$ type friction stabilisers, installed in large $(4.5 \times 4.5 \mathrm{~m})$ trackless development ends (Figure 9).

- For the deep, fractured environment, a combination of resin-grouted rebars and fibre-reinforced shotcrete (fibrecrete), installed in smaller-dimension $(3.5 \times 3.5 \mathrm{~m})$ rail-bound development ends (Figure 10).

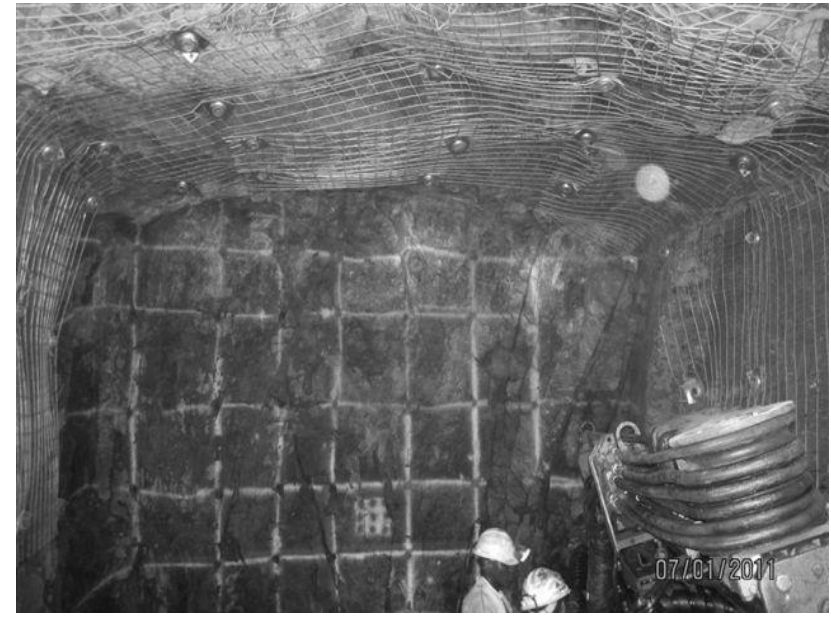

Figure 9 Showing welded mesh and friction stabilisers installed in shallow blocky ground conditions

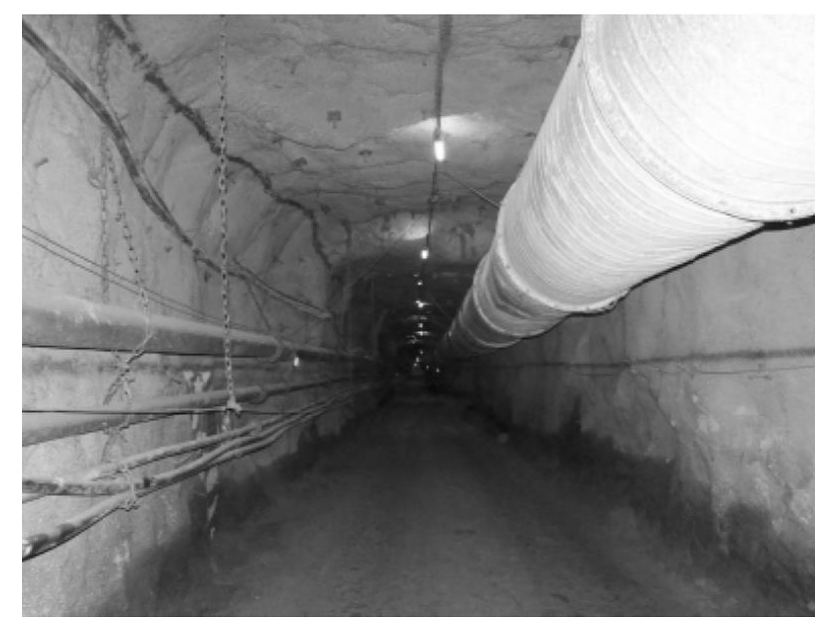

Figure 10 Showing fibrecrete and resin-grouted rebars in deep, fractured ground conditions

As described by in a paper prepared for the 2011 Beijing Congress hosted by the International Society for Rock Mechanics (Gardner, 2011), both systems have proven to be practically implementable, and both these sections have gone without a rock related injury or incident over a sustained period.

In addressing the stability risk, both options provide full areal coverage and zero exposure to unsupported rock after development. There are, however, several limitations to both systems:

- Welded mesh and friction stabilisers.

- The only effective way to pin successive sheets of welded mesh in place is using friction stabilisers - smaller-diameter units are pushed into the back end of already-installed largerdiameter units, rather than loosening and re-tensioning nuts and washer as would be the case for threaded tendons. This operation also usually requires the use of a double-boom drill rig - one boom pins a corner of the mesh sheet while the other manoeuvres it into place. Under fractured conditions (particularly with micro-fractured slabs), unless shotcrete is 
applied very soon after mesh installation, it is likely that the rock will fracture behind the mesh, requiring the mesh to be cut open and the rock 'bled' before shotcreting.

- Friction stabilisers require additional bond length to suspend similar loads to other tendons, necessitating tighter hole tolerances and longer units. Being thin-walled and open-ended, they are susceptible to corrosion, particularly in aggressive environments (such as at No. 16 shaft). Their load-bearing capability is also significantly affected by dynamic loading, requiring double the normal bond length under these circumstances. Both corrosion resistance and dynamic performance can apparently be improved by post-grouting, but this needs to be tested and proven.

- Shotcrete and resin-grouted rebars.

- Shotcrete performance, especially fibrecrete, can be dramatically affected by incorrect dosage of chemicals, poor mixing, substandard application process, etc. Application thickness control also needs to be carefully checked, particularly on the hanging wall.

- Minimising the bond length of resin-grouted rebars depends on several factors, including an optimal annulus between rebar and hole sidewall, drilling the correct length of hole, inserting sufficient capsules to achieve complete hole filling and following set installation procedures, particularly holding times to allow the resin to set properly. To compensate for these issues, increased bond lengths are normally specified.

\subsection{Merging machinery, methodology, dimensions and cycle time}

As projects have progressed, experience produced some valuable lessons with regard to matching machinery to excavation dimensions. These include:

- Near-ideal development end dimensions for different mining methodologies.

- Minimum dimensions required for machines to operate productively and safely.

- Different machines' ability to drill certain hole dimensions and install different support units.

- Practical activity sequences to ensure optimal mining shift utilisation with minimum risk.

- Benchmarked cycle times for drilling, cleaning and supporting ends.

Two successful examples of this process are:

- The trackless development of the main incline and decline spines at No. 20 shaft, supported by a combination of Split Set-type friction stabilisers and sheets of welded 'Aussie' mesh, installed by drill rigs in large trackless development ends $(4.5 \times 4.5 \mathrm{~m})$. Barring is accomplished by 'rattling' with the drill rig, so no personnel are exposed. Cleaning is done by LHD (with operator in a cabin under permanent support) and the blast round length is $3.0 \mathrm{~m}$.

- The rail-bound development to reef on the upper levels of No. 16 shaft, supported by a combination of resin-grouted rebars (installed by handheld rock drill or rail-bound drill rig) and shotcrete (applied by handheld spraying and mixed in purpose-built agi-cars), installed in the smaller-dimension $(3.5 \times 3.5 \mathrm{~m})$ rail-bound development ends. Barring is currently undertaken manually with personnel exposure, but the rail-bound drills rigs could possibly be modified to carry out 'rattling'. Cleaning is done by rocker shovel. Blast rounds have been reduced to $2.0 \mathrm{~m}$ to keep the rocker shovel operator within $1.0 \mathrm{~m}$ of permanent support and to reduce the exposed distance for manual barring.

\section{$5 \quad$ Options going forward}

In line with international leading practice to eliminate all personnel exposure to unsupported rock during any phase of mining, a number of possible alternatives have been investigated by the project team and 
support staff. From a purist's viewpoint, the new approach would require at least six machine functions to complete the mining cycle with the current support system - scaler, LHD, robot shotcreter and agi-car, roofbolter, drill rig and utility vehicle/scissor lift.

Discussions with representatives from mining contracting companies, equipment manufacturers and other mining professionals, coupled with wide-ranging research, have indicated that with minor modifications, the mining cycle can be performed with three machines - LHD (cleaning), drill rig ('rattling', tendon installation, cable anchor hole drilling and face drilling) and utility vehicle/scissor lift (shotcrete mixing and application, charging up and pipe/column/cable installation).

Two possible support systems have been identified, namely:

1. Fibrecrete up to the face and resin-grouted rebar tendons, with cable anchors where required this is being used by Byrnecut Mining (Pty) Ltd at the Telfer Mine in Australia and at Palabora Mine in South Africa. This would be the first choice, given the potential for an aggressively corrosive atmosphere such as at No. 16 shaft once the chloride-containing Hex River fault is intersected. Fibrecreting up to the face will have a significantly detrimental impact on cycle times and hence advance rates and some innovative thinking and use of industrial engineering techniques will be required in order to optimise the cycle.

2. Galvanised welded mesh pinned by friction anchors at the face, followed within 24 hours, i.e. the next blasting cycle, by normal (unreinforced) shotcrete, cable anchors and post-grouting of friction anchors with a shepherd's crook-type unit inserted into the grout for suspension or lacing. This system uses a different cycle, which disconnects the shotcrete, post-grouting and anchor installation from the face supporting and face drilling activities, thus allowing concurrent operation. This system is undergoing investigation and shows promise.

\section{Conclusions}

This paper attempts to explain the holistic approach followed at Impala to design and specify support systems for a variety of depths and geotechnical environments without delving unnecessarily into too much technical detail. The different parameters requiring evaluation have been highlighted and two successful strategies have been presented. Finally, potential solutions for development at future deep mining projects have been identified and proposed.

\section{References}

Barton, N., Lien, R. and Lunde, J. (1974) Engineering Classification of Rock Masses for the Design of Tunnel Support, Rock Mechanics Journal, Vol. 6, No. 4, pp. 189-236.

Gardner, L.J. (Latest update September 2012) Code of Practice to prevent Rock Fall and Rock Burst Accidents, Internal Impala Platinum Limited document, $28 \mathrm{p}$.

Gardner, L.J. (2011) Experiences with Tunnel Support in a South African Platinum Mine, in Proceedings ISRM 12th International Congress on Rock Mechanics, 16-21 October 2011, Beijing, China, pp. 1,495-1,499.

Jager, A.J. and Ryder, J.A. (1999) A Handbook on Rock Engineering Practice for Tabular Hard Rock Mines, Safety in Mines Research Advisory Committee, Creda Communications, Johannesburg, pp. 148-150. 